\title{
Free Surface Energy Change for Water Adsorbed on Hydroxyapatite
}

\author{
Hillar M. Rootare and Robert G. C.raig
}

University of Michigan School of Dentistry, Ann Arbor, Michigan 48109, USA.

The free energies of immersion for three hydroxyapatite samples of different origin and method of preparation were determined from zeater adsorption isotherms at 20 and $25 \mathrm{C}$. The free energies varied with the temperature of the isotherm, changing linearly with the outgassing temperature in the range of 20 and $300 \mathrm{C}$. The samples outgassed at $300 C$ yielded free energy of immersion values of 365,432 , and 476 ergs/ $\mathrm{cm}^{2}$ for the VIC-, NBS-, and TVA-HAP, respectively. Work of adhesion and work of spreading were calculated for water on these samples.

\section{J Dent Res 56(7): 744-747 July, 1977 .}

In 1878 , Gibbs derived thermodynamically a differential equation for adsorption when the bulk concentration of the solute, $\mathrm{C}$, the number of molecules, $\mathrm{n}$, adsorbed per $\mathrm{cm}^{2}$ of surface, and the change in free energy of the surface, was related to the change in concentration of the solute at constant temperature, $(\partial \gamma / \partial \mathrm{C})_{\mathrm{T}}$. The derivation of the Gibbs' adsorption equation has been presented in the literature ${ }^{1-6}$ and is given as

$$
(\partial \gamma)_{T}=\Sigma \operatorname{nn}(\partial \mu)_{\mathrm{T}}
$$

where the summation includes all adsorbed species and $\mu$ is the chemical potential.

Boyd and Livingston ${ }^{7}$ and Harkins and coworkers $^{8-10}$ used the Gibbs' equation to develop the following equation for determining the free surface energy change for vapors adsorbed on nonporous solids.

$$
\begin{gathered}
-\Phi_{\mathrm{So}_{\mathrm{SL}}}=\gamma_{\mathrm{SO}}-\gamma_{\mathrm{SL}}= \\
\frac{\mathrm{RT}}{\mathrm{MA}} \int_{\mathrm{s}}^{\mathrm{p} / \mathrm{p}_{\mathrm{o}}=1} \mathrm{x} / \mathrm{md} \ln \mathrm{p} / \mathrm{p}_{\mathrm{o}}+\gamma_{\mathrm{LYO}},
\end{gathered}
$$

Received for publication June 21, 1976

Accepted for publication August 13, 1976.

This research was supported in whole by the $\mathrm{Na}$ tional Institutes of Health, National Institute of Dental Research Training Grant No. T01 DE-00181.

Paper presented in part at the International Association for Dental Research 50th General Meeting, Las Vegas, Nevada, March 1972. where $-\Phi_{\text {so }}$ represents the change in the free surface energy when one $\mathrm{cm}^{2}$ surface of solid-vacuum interface is replaced by solidliquid interface. Free surface energy, surface tension, or interfacial tension is represented by $\gamma$ and the subscripts have the following meanings: $\mathrm{SO}=$ solid-vacuum, $\mathrm{SL}=$ solid-liquid, and $\mathrm{LV}^{\circ}=$ liquid-saturated vapor. The adsorbate molecular weight is $M$, the specific area is $\mathrm{A}_{\mathrm{S}}$, the weight adsorbed in $\mathrm{mg} / \mathrm{g}$ of adsorbent is $\mathrm{x} / \mathrm{m}$, and the relative pressure of the adsorbate is $\mathrm{p} / \mathrm{p}_{0}$.

The free surface energy change on adsorption of a vapor on a solid from vacuum to saturation $\left(\mathrm{SV}^{\circ}\right)$ is,

$$
\begin{aligned}
& \Phi_{\mathrm{so} / \mathrm{sv}^{\circ}}=\gamma_{\mathrm{so}}-\gamma_{\mathrm{sv}^{\circ}}= \\
& -\frac{R T}{M A_{S}} \int_{p / p_{0}=0}^{p / p_{0}=1} x / p_{0} .
\end{aligned}
$$

At saturation a liquid film is formed and if no contact angle is formed then

$$
\gamma_{\mathrm{So}}-\gamma_{\mathrm{SV}}{ }^{\circ}=\gamma_{\mathrm{So}}-\gamma_{\mathrm{SL}}-\gamma_{\mathrm{LV}}
$$

and the free energy change can be writeen as

$$
\begin{aligned}
& \gamma_{\mathrm{SO}}-\gamma_{\mathrm{SL}}-\gamma_{\mathrm{LV}}= \\
& \frac{\mathrm{RT}}{\mathrm{M} / \mathrm{p}_{\mathrm{o}}=1} \int_{\mathrm{p} / \mathrm{p}_{\mathrm{o}}=0}^{\mathrm{x} / \mathrm{m} \mathrm{ln} \mathrm{ln} / \mathrm{p}_{\mathrm{u}} .}
\end{aligned}
$$

Since the work of adhesion, $\mathrm{Wa}$, is defined as

$$
W_{\mathrm{a}}=\gamma_{\mathrm{SO}}-\gamma_{\mathrm{SL}}+\gamma_{\mathrm{LV}} \text {, }
$$

it may be expressed for a nonporous solid in terms of the Cibbs' adsorption equation as

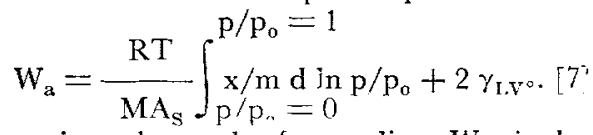

Also, since the work of spreading; $W_{s}$, is defined as

$$
\mathrm{W}_{\mathrm{s}}=\mathrm{W}_{\mathrm{a}}-\mathrm{W}_{\mathrm{s}}
$$

where $W_{c}$, the work of cohesion, is equal to 2 $\gamma_{L^{\circ}}, W_{\mathrm{s}}$ can be expressed as

$$
W_{\mathrm{s}}=\frac{\mathrm{RT}}{\mathrm{MA}_{\mathrm{s}}} \int_{\mathrm{p} / \mathrm{p}_{0}=0}^{\mathrm{p} / \mathrm{p}_{\mathrm{o}}=1} \mathrm{x} / \mathrm{m} \mathrm{ln} \text {. }
$$


It is apparent that the various quantities described above can be determined if the integral can be calculated, the surface area of the solid measured, and the surface tension of water, $\gamma_{1, V^{\circ}}$, is known.

It is the purpose of this study to determine. the frce energy of immersion, $\gamma_{\mathrm{SO}}-\gamma_{\mathrm{SL}}$, the work of adhesion, and the work of spreading of water on various hydroxyapatites. Also, the change in the free energy of immersion as a function of temperature will be determined.

\section{TABLE 1}

Gapillary Condensation of Water in HaP COMPAGTS ON ADSORPTION

\begin{tabular}{lccc}
\hline \hline HAP & $\begin{array}{c}\text { Maximum } \\
\text { Adsorbed Volume } \\
\text { cc/g }\end{array}$ & $\begin{array}{c}\text { Pore } \\
\text { Volume } \\
\text { cc/g }\end{array}$ & $\begin{array}{c}\text { Fraction } \\
\text { Pore Volume } \\
\text { Filled }\end{array}$ \\
\hline VIC & 0.173 & 0.507 & 0.340 \\
NBS & 0.0652 & 0.412 & 0.158 \\
TVA & 0.0134 & 0.358 & 0.038 \\
\hline
\end{tabular}

\section{Materials and Methods}

The hydroxyapatite (HAP) samples and their methods of preparation are the same as those described by Craig and Rootare. ${ }^{11}$

The adsorption isotherms of water on HAP were determined on compacts as described by Rootare and Craig ${ }^{12}$ using a gravimetric adsorption balance at isotherm temperatures of 20 and $25 \mathrm{C}$. All samples were compacted at 4,450 $\mathrm{N}(1,000 \mathrm{lbs})$ load on a $\mathrm{I} / 2$ inch diameter ram for two minutes. The compacts generally were outgassed at $300 \mathrm{C}$ and it should be assumed that the temperature was $300 \mathrm{C}$ unless otherwise specified.

Adsorption isotherms were determined from $\mathrm{p} / \mathrm{p}_{0}$ equal to zero to $\mathrm{p} / \mathrm{p}_{\mathrm{o}}$ of nearly one. The integral in equation 2 and others was deter- mined graphically from plots of $\mathrm{x} / \mathrm{m}$ versus in $\mathrm{p} / \mathrm{p}_{\mathrm{o}}$ from $\mathrm{p} / \mathrm{p}_{\mathrm{c}}=0$ to $\mathrm{p} / \mathrm{p}_{\mathrm{o}}=1$. The integral was evaluated by a computer program using Simpson's rule. ${ }^{13}$ The free surface energy changes per unit area were calculated using surface areas of the HAP compacts determined from B.E.T. plots of water adsorption isotherms.

\section{Results}

The compacts were shown to be incompletely filled with water at saturation during the isotherm determinations and the pore volume, maximum adsorbed volume, and the fraction of the pore volume filled for Victor (VIC), National Bureau of Standards (NBS), and Tennessee Valley Authority (TVA) compacts are listed in Table 1. The fraction of the pore volume filled at saturation varied about tenfold from a low value of 0.038 for TVA-HAP to a high value of 0.340 for VIC-HAP. The highest value of 0.340 for VIC-HAP, however, showed that $66 \%$ of the pore volume was not filled at saturation, and therefore the compacts could be classed as nonporous for the purposes of the Gibbs' adsorption equation.

The free energy of immersion of water on the three hydroxyapatites at 20 and $25 \mathrm{C}$ are given in Table 2. A large temperature dependence of the free energy of immersion existed for all three hydroxyapatites but in addition the free surface enersy changes of the hydroxyapatites varied significantly. The order of the values of the three hydroxyapatites was the same for either 20 or $25 \mathrm{C}$ with VIC-HAP having the lowest values and 'TVA-HAP having the highast values at a given temperature.

Since the work of adhesion and the work of spreading are the tree energy of immersion plus $\gamma_{L V^{\circ}}$, the surface tension of water, or minus $\gamma_{L V}$ othe same trends in values were observed

TABLE 2

Free Enercy of Immersion, Work of Adhesion and Work of Spreading of Water on Hydroxyapatite at 20 and 25 C

\begin{tabular}{|c|c|c|c|c|c|c|}
\hline & \multirow{2}{*}{\multicolumn{2}{|c|}{$\frac{\text { Free Energy of Immersion }}{\gamma_{\mathrm{SO}}-\gamma_{\mathrm{SL}}, \text { ergs } / \mathrm{cm}^{2}}$}} & \multicolumn{2}{|c|}{ Work of Adhesion } & \multicolumn{2}{|c|}{ Work of Spreading } \\
\hline & & & \multicolumn{2}{|c|}{$\gamma_{S O}-\gamma_{S I}+\gamma_{L V 0}$, ergs $/ \mathrm{cm}^{2}$} & \multicolumn{2}{|c|}{$\gamma_{\mathrm{SO}}-\gamma_{\mathrm{SL}}-\gamma_{\mathrm{LV}}, \mathrm{ergs} / \mathrm{cm}^{2}$} \\
\hline & $20 \mathrm{C}$ & $25 \mathrm{C}$ & $20 \mathrm{C}$ & $25 \mathrm{C}$ & $20 \mathrm{C}$ & $25 \mathrm{C}$ \\
\hline \multirow[t]{2}{*}{ VIC } & 365.3 & 234.5 & 438.3 & 306.5 & 293.0 & 162.5 \\
\hline & $(2.6) *$ & $(2.5)$ & $(2.6)$ & $(2.5)$ & $(2.3)$ & $(2.5)$ \\
\hline \multirow[t]{2}{*}{ NBS } & 432.5 & 373.5 & 505.5 & 445.5 & 359.5 & 301.5 \\
\hline & $(22.5)$ & $(11.5)$ & $(22.5)$ & $(11.5)$ & $(22.5)$ & $(11.5)$ \\
\hline \multirow[t]{2}{*}{ TVA } & 476.3 & 407.3 & 549.3 & 479.0 & 403.3 & 335.0 \\
\hline & $(7.1)$ & $(2.3)$ & $(7.1)$ & $(2.1)$ & $(7.1)$ & $(2.3)$ \\
\hline
\end{tabular}

* Numbers in parentheses are standard deviations. 
TABLE 3

Change in Free Energy of Immersion of WATER ON HydROXYAPATITE WITH TEMPERATURE

\begin{tabular}{|c|c|c|c|c|}
\hline \multirow[b]{2}{*}{ HAP } & \multirow{2}{*}{$\begin{array}{c}\text { Surface } \\
\text { Area* } \\
\mathrm{m}^{2} / \mathrm{g}\end{array}$} & \multicolumn{2}{|c|}{$\gamma_{\mathrm{SO}}-\gamma_{\mathrm{SL}}$} & \multirow{2}{*}{$\frac{\Delta\left(\gamma_{\mathrm{SO}}-\gamma_{\mathrm{SL}}\right)}{\Delta \mathrm{T}} \frac{\mathrm{ergs} / \mathrm{cm}^{2} / \mathrm{C}}{n^{2}}$} \\
\hline & & $\begin{array}{c}20 \mathrm{C} \\
\mathrm{ergs} / \mathrm{cm}^{2}\end{array}$ & $\begin{array}{c}25 \mathrm{C} \\
\mathrm{ergs} / \mathrm{cm}^{2}\end{array}$ & \\
\hline VIC & 66.3 & 365. & 234. & -26 \\
\hline NBS & 21.2 & 432. & 374. & -12. \\
\hline TVA & 2.98 & 476. & 407. & -14. \\
\hline
\end{tabular}
therms.

* Determined from B.E.T. water adsorption iso-

for $W_{\mathrm{a}}$ and $\mathrm{W}_{\mathrm{s}}$ as with the free energy of immersion (see Table 2).

The change in the free energy of immersion of water on HAP with temperature is given in Table 3. The temperature cocfficient of the free energy of immersion of NBS and TVA were of the same magnitude, -12 and -14 - ergs ${ }^{\prime}$ $\mathrm{cm}^{2} / \mathrm{C}$ while the temperature coefficient for VIC-HAP was about twice these values, or $-26 \cdot \mathrm{ergs} / \mathrm{cm}^{2} / \mathrm{C}$.

The effect of outgassing temperature on the free energy of immersion of water on hydroxyapatite is shown in Figure 1 for temperatures from 20 to $300 \mathrm{C}$. The values for VIC-HAP are plotted $\mathrm{f} c \mathrm{r}$ isotherm temperatures of 20 and $25 \mathrm{C}$, those for NBS-HAP at $25 \mathrm{C}$ and those for TVA-HAP at $20 \mathrm{C}$. The free energy of immersion values increase linearly with outgassing temperature from 20 to $300 \mathrm{G}$. The values appear to converge near $0 \mathrm{C}$ at the enthalpy of water, $118 \mathrm{ergs} / \mathrm{cm}^{2}$. The rate of change in the free energy of immersion with increasing outgassing temperature for the three HAP samples can be noted from the slopes of the lines in Figure 1 and the values for the slopes are listed in Table 4 . The difference in the slopes at the two isotherm temperatures is also given in Table 4 as is the change in slopes per degree of the isotherm temperature difference (the second derivative of the temperature dependency). These latter values represent the effect of the

TABLE 4

Change in Free Energy of Immersion with OUtgassing Temperature

\begin{tabular}{|c|c|c|c|c|}
\hline \multirow[b]{2}{*}{ HAP } & \multicolumn{2}{|c|}{$\begin{array}{c}\text { Slope } \\
\Delta \phi / \Delta T, \text { ergs } / \mathrm{cm}^{2} / \mathrm{C}\end{array}$} & \multirow[b]{2}{*}{$\Delta \underset{3}{\operatorname{Slope}}$} & \multirow{2}{*}{$\begin{array}{c}\Delta \text { Slope } \\
\Delta \mathrm{T} \\
\mathrm{ergs} / \mathrm{cm}^{2} / \\
\mathrm{C} / \mathrm{C} \\
4\end{array}$} \\
\hline & $\begin{array}{r}20 \mathrm{C} \\
1\end{array}$ & $\underset{2}{25 \mathrm{C}}$ & & \\
\hline & 0.75 & 30 & 0.40 & -0.081 \\
\hline B & 1.0 & & & -0.055 \\
\hline TVA & 1.273 & 1.043 & 0.230 & -0.046 \\
\hline
\end{tabular}

isothermal temperature change superimposed on the outgassing temperature effect on the change of the free energy of immersion. The isothermal temperature coefficient (column 4, Table 4) for the change of free cnergy of immersion varied only slightly between NBS- and TVA-HAP $(-0.055$ and -0.046$)$ while it was about $50 \%$ higher for VIC-HAP $(-0.081)$.

\section{Discussion}

The highest surface area sample, VIC-HAP, had the lowest free energy of immersion, 365 ergs $/ \mathrm{cm}^{2}$ at $20 \mathrm{C}$ while the lowest surface area sample, TVA-HAP, had the highest value of $476 \mathrm{ergs} / \mathrm{cm}^{2}$ at $20 \mathrm{C}$. This difference of 111

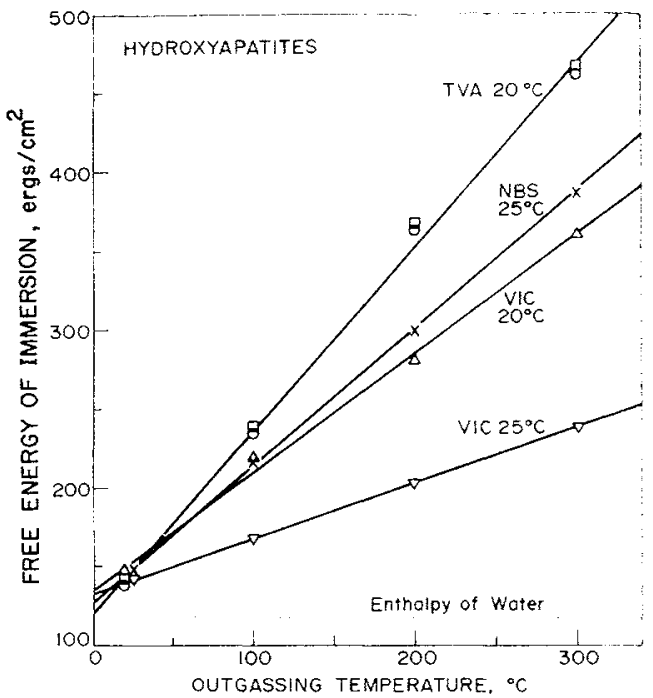

FIG 1.-The free energy of immersion as a function of outgassing temperature for the water vapor adsorption isotherms on hydroxypatite samples at 20 and $25 \mathrm{C}$.

ergs $/ \mathrm{cm}^{2}$ is about a $23 \%$ difference in energy which is large considering that Linde silica ${ }^{14}$ and graphite ${ }^{15}$ had total free energy of immersion values for water of 140 and $37 \mathrm{ergs} / \mathrm{cm}^{2}$, respectively. The work of adhesion and work of spreading follow the same sequence as the free energy of immersion since they differ by the constant factors $+\gamma_{L V^{\circ}}$ and $-\gamma_{L V^{\circ}}$.

The outgassing of HAP in vacuum from 20 to $300 \mathrm{G}$ had a linear effect on the free energy of immersion which on the average approached the enthalpy of water at $0 \mathrm{C}$. Outgassing involved stripping of water off the surface and showed that at room temperature the samples, even after evacuation for 24 hours, were mostly covered with water at the isothermal tempera- 
ture. The water remained strongly adsorbed and was not removed until heat energy was added by increasing the outgassing temperature. The rate of change in the free energy of immersion with increasing outgassing temperature was different for the hydroxyapatite samples but NBS-HAP and TVA-HAP were similar and VIC-HAP was very different in its thermal behavior.

Although the three HAP samples adsorbed approximately the same number of water molecules per unit area ${ }^{12}\left(9.2 / 100 \AA^{2}\right)$ the free energy changes in the adsorption of the water were greatly different. For example, the free surface energy change for water on VIC-HAP was about $77 \%$ of that of TVA-HAP. The binding energies of water removed at $300 \mathrm{C}$ were reported ${ }^{12}$ to be $5.6,4.9$, and $3.9 \mathrm{Kcal} /$ mole of water adsorbed on TVA-, NBS-, and VIC-HAP, respectively. Hydroxyapatites with the highest binding energy also had the highest free energy of immersion (TVA-HAP) and the hydroxyapatite with the lowest binding energy had lowest free energy of immersion (VICHAP).

It is apparent that although crystallographically the hydroxyapatites were nominally the same and the adsorption capacities per unit area also were the same, the surface energies of the hydroxyapatite samples were distinctly different. Determination of free surface energy changes is, therefore, of importance in characterizing the surface of hydroxyapatite or tooth enamel.

\section{Conclusion}

The free energy of immersion of water on hydroxyapatites was determined from vapor phase adsorption isotherms at 20 and $25 \mathrm{C}$. The free energy of immersion of water on HAP at $20 \mathrm{C}$ was approximately 476,432 , and 365 ergs $/ \mathrm{cm}^{2}$ for TVA-, NBS-, and VIC-HAP outgassed at $300 \mathrm{C}$. The free energies of immersion of all three hydroxyapatites decreased at the isotherm temperature of $25 \mathrm{C}$ with decreases of about $14 \%$ for NBS- and TVA-HAP and of $36 \%$ for VIC-HAP.

The free energy of immersion values decreased linearly for sample outgassed from 300 to $20 \mathrm{G}$ with the values approaching the enthalpy of water at $0 \mathrm{C}$. The free energy of immersion values for the three hydroxyapatites were in the same order as the binding energies of water at $300 \mathrm{C}$.

The free surface energy changes for water on hydroxyapatite were distinctly different for VIC-, TVA-, and NBS-HAP although they were crystallographically similar and adsorbed the same number of water molecules per unit area. Vapor phase adsorption is, therefore, a powerful tool in characterizing of hydroxyapatites and mineral portions of tooth enamel.

\section{References}

1. GibBs, J.W.: Collected Works, Vol. 1, Yale University Press, 1948, 219 pp.

2. Adamson, A.W.: Physical Chemistry of Surfaces, 2nd ed., New York, Interscience, 1967, p 65.

3. Bangham, D.H.: The Gibbs Adsorption Equation and Adsorption on Solids, Trans Faraday Soc 33:805-811, 1937.

4. BANGhaM, D.H., and Razouk, R.I.: Adsorption and Wettability of Solid Surfaces, Trans Faraday Soc 33:1459-1463, 1937.

5. Davies, J.T., and RideAl, E.K.: Interfacial Phenomena, 2nd ed., New York, Academic Press, 1963, p 196.

6. GreGG, S.J., and Sing, K.S.W.: Adsorption Surface Area and Porosity, New York, Academic Press, 1967, p 234.

7. Boyd, G.E., and Lrvingston, H.K.: Adsorption and the Energy Changes at Crystalline Solid Surfaces, $J$ Am Chem Soc, 64: 2383-2388, 1942.

8. Jura, George, and Harkins, W.D.: Surface Solids, XI, Determination of the Decrease $(\pi)$ of Free Surface Energy of a Solid by an Adsorbed Film, $J$ Am Chem Soc 66: 1356-1362, 1944.

9. Loeser, E.H.; Harkins, W.D.; and Twiss, S.B.: Adhesion of Liquids to Solids, Molecular Interaction between Metal Oxides and Adsorbed Vapors, $J$ Phys Chem 57:251-254, 1953.

10. Loeser, E.H.; Harkins, W.D.; and Twiss, S.B.: Molecular Interaction between n-Propyl Alcohol and Iron or Iron Oxide, J Phys Chem 57:591-597, 1953.

11. CRaig, R.G., and Rootare, H.M.: Heats of Solution of Apatites, Human Enamel, and Dicalcium-Phosphate, in Dilute Hydrochloric Acid (in Ponter, R.S., and Johnson, J.F., eds) Analytical Calorimetry, Vol. 3, New York, Plenum Press, 1974, pp 397-404.

12. Rootare, H.M. and Cratg, R.G.: Vapor Phase Adsorption of Water on Hydroxyapatite, $J$ Dent Res, in press.

13. Rootare, H.M.: Free Surface Energies, Heats of Solution and Heats of Immersion of Calcium Apatite Powders, Dissertation; University of Michigan, 1973, $457 \mathrm{pp}$.

14. Van Voorhis, J.J.; Graig, R.G.; and BarTELL, F.E.: Free Energy of Immersion of Compressed Powders with Different Liquids, II, Silica Powders, J Phys Chem 61:15131519, 1957.

15. CRArG, R.G.: Energy of Immersion of Graphite powders with Different Liquids, Dissertation, University of Michigan, 1954, $175 \mathrm{pp}$. 